\title{
Efecto de tres tratamientos sobre la filancia del semen y su relación con la calidad espermática en alpacas (Vicugna pacos)
}

\author{
Effect of three treatments on the seminal filancia and its relationship with sperm \\ quality in alpacas (Vicugna pacos)
}

\author{
Andrés A. Ramírez R. ${ }^{1}$, Walter Palomino-Guerrera ${ }^{1,3}$, Mijaíl Contreras ${ }^{1}$, \\ Cesar Olaguivel ${ }^{2}$
}

\section{Resumen}

El estudio tuvo como objetivo evaluar el efecto de la colagenasa, pipeteo e incubación para disminuir la filancia del semen y su relación con la calidad espermática en alpacas para su criopreservación. Las muestras de semen se obtuvieron por vagina artificial de machos de 4-7 años en el Laboratorio de Biotecnología Reproductiva de la Estación Experimental Agraria Canaán del INIA (Ayacucho, Perú). Se evaluó las características macroscópicas (volumen, $\mathrm{pH}$ y filancia) y microscópicas (motilidad, concentración y vitalidad) del semen. Cada muestra se distribuyó en tres alícuotas y diluida con dilutor comercial AndroMed ${ }^{\circledR}$ en proporción de $1: 1$ a $37^{\circ} \mathrm{C}$ y distribuidas en tratamientos: $\mathrm{T} 1=$ Colagenasa al $5 \%$; T2=Pipeteo 10 veces y T3=Incubación a $37^{\circ} \mathrm{C}$ durante $10 \mathrm{~min}$. Las características microscópicas se evaluaron a los 0, 20, 40, 60 y 120 min pos-dilución. La filancia disminuyó significativamente de $0.95,0.89$ y $0.91 \mathrm{~cm}$ a $0.26,0.27$ y $0.33 \mathrm{~cm}$ a los 120 min pos-dilución para $\mathrm{T} 1, \mathrm{~T} 2$ y T3, respectivamente $(\mathrm{p}<0.05)$, pero sin diferencias entre

\footnotetext{
${ }^{1}$ Laboratorio de Biotecnología Reproductiva, Estación Experimental Agraria Canaán, Instituto Nacional de Innovación Agraria, Ayacucho, Perú

${ }^{2}$ Laboratorio de Producción y Salud en Camélidos Sudamericanos, Medicina Veterinaria, Universidad Nacional de San Cristóbal de Huamanga, Ayacucho, Perú

${ }^{3}$ E-mail: mvpalomino92@gmail.com
}

Recibido: 30 de abril de 2021

Aceptado para publicación: 12 de noviembre de 2021

Publicado: 22 de diciembre de 2021

CLos autores. Este artículo es publicado por la Rev Inv Vet Perú de la Facultad de Medicina Veterinaria, Universidad Nacional Mayor de San Marcos. Este es un artículo de acceso abierto, distribuido bajo los términos de la licencia Creative Commons Atribución 4.0 Internacional (CC BY 4.0) [https:// creativecommons.org/licenses/by/4.0/deed.es] que permite el uso, distribución y reproducción en cualquier medio, siempre que la obra original sea debidamente citada de su fuente original 
tratamientos. La motilidad espermática y la vitalidad no fueron afectadas por los tiempos pos-dilución, pero la motilidad disminuyó significativamente $(\mathrm{p}<0.05)$ luego de la dilución del semen. Se concluye que el uso de colagenasa, pipeteo e incubación disminuyeron la filancia del semen de alpaca pos-dilución, afectando la motilidad y vitalidad espermática.

Palabras clave: colagenasa, pipeteo, incubación, filancia, semen, alpaca

\section{Abstract}

The aim of this study was to evaluate the effect of collagenase, pipetting and incubation to reduce the filancia of semen and its relationship with sperm quality in alpacas for its cryopreservation. Semen samples were obtained by artificial vagina from 4-7-year-old males at the Reproductive Biotechnology Laboratory of the Canaán Agrarian Experimental Station of INIA (Ayacucho, Peru). The macroscopic (volume, $\mathrm{pH}$ and filancia) and microscopic (motility, concentration and vitality) characteristics of the semen were evaluated. Each sample was distributed in three aliquots and diluted with the commercial AndroMed ${ }^{\circledR}$ extender in a $1: 1$ ratio at $37^{\circ} \mathrm{C}$ and subjected to three treatments: $\mathrm{T} 1=$ Collagenase $5 \% ; \mathrm{T} 2=$ Pipetting 10 times, and $\mathrm{T} 3=$ Incubation at $37^{\circ} \mathrm{C}$ for $10 \mathrm{~min}$. The microscopic characteristics were evaluated at $0,20,40,60$ and $120 \mathrm{~min}$ post-dilution). The filancia decreased significantly from $0.95,0.89$ and $0.91 \mathrm{~cm}$ to $0.26,0.27$ and $0.33 \mathrm{~cm}$ at 120 min post-dilution for $\mathrm{T} 1, \mathrm{~T} 2$ and $\mathrm{T} 3$, respectively $(\mathrm{p}<0.05)$, but without differences between treatments. Sperm motility and vitality were not affected by post-dilution times, but motility decreased significantly $(p<0.05)$ after semen dilution. It is concluded that the use of collagenase, pipetting, and incubation decreased the filancia of post-dilution alpaca semen, affecting sperm motility and vitality.

Key words: collagenase, pipetting, incubation, filancia, semen, alpaca

\section{INTRODUCCIÓN}

Las biotecnologías reproductivas facilitan el progreso genético de los animales de producción (Cabrera y Yoong, 2009). La inseminación artificial (IA) como técnica reproductiva en los camélidos sudamericanos (CSA) aún no ha sido desarrollada completamente, en parte debido a la baja eficiencia de los procedimientos rutinarios existentes para el congelamiento de semen de estas especies (Gómez-Quispe et al., 2016). El éxito de esta técnica depende de las características biofísicas de los eyaculados, así como de los métodos para su procesamiento que aseguren una pérdida mínima de capacidad fecundante (Mostafa et al., 2014).
El semen es una sustancia líquida que contiene las células sexuales (espermatozoides) y las secreciones de los órganos accesorios del macho (Hafez, 2002). El mantenimiento de la capacidad fecundante de los espermatozoides debe tenerse en cuenta al implementar nuevas técnicas de criopreservación (Aller et al., 2003); sin embargo, se han tenido resultados insatisfactorios para la alpaca debido a la alta variabilidad de las características propias del semen (volumen, color, concentración, vitalidad y motilidad) (Bravo et al., 2000), la técnica de colección (Morton et al., 2006), la alta viscosidad (Rateb, 2016), la filancia y el uso de dilutores (Delgado y Quispe, 2015). Ante esto, se necesita priorizar investigaciones en alternati- 
vas biotecnológicas para el mejoramiento genético en los camélidos domésticos (Huanca et al., 2007).

Los protocolos de congelación de semen de alpaca se vienen modificando con la finalidad de mejorar la viabilidad y fertilidad espermática al descongelado (Stornelli et al., 2005). Se indica que la viscosidad y filancia del semen se debe a la presencia de mucopolisacáridos en las secreciones de las glándulas bulbouretrales (Gonzáles, 2003). Hay estudios que utilizaron enzimas como la fibrinolisina, hialuronidasa, tripsina (Bravo et al., 2000) y colagensa (Giuliano y Casaretto, 2011), siendo efectivas para disminuir la viscosidad del semen de alpaca y llama. Así también, se han evaluado métodos mecánicos como la aspiración y expulsión del eyaculado a través de una aguja (Apaza et al., 2001) y sometido a centrifugación (Bérgamo et al., 2012), que han mostrado eficacia sobre la viscosidad sin alterar los parámetros seminales (Turín et al., 2013; Zirena, 2014).

Muchas de las alteraciones estructurales y funcionales de los espermatozoides están relacionadas con la producción excesiva de radicales libres (RL) en el proceso de congelamiento (Tortolero et al., 2005), la cuál estaria alterando el potencial de membrana mitocondrial (PMM) que tiene relacion directa con la motilidad (Allauca et al., 2019). Ante esto, los laboratorios empezaron a utilizar antioxidantes como Tempol, catalasa (GómezQuispe et al., 2016; Muchotrigo, 2017), genisteína (Elsayed et al., 2019) y metil- $\beta$ ciclodextrina cargada con el colesterol (Ciprian, 2018), así como sustratos energéticos (Quispe et al., 2019), mejorando la vitalidad, funcionalidad de membrana, motilidad progresiva de espermatozoides en refrigeración y congelación/descongelación.

La preservación de semen es un reto para el desarrollo de la crianza de camélidos sudamericanos (Bravo et al., 2013), dadas las caracteristicas particulares de filancia y viscosidad del semen (Kershaw-Young et al., 2013), debiendo desarrollarse nuevas técni- cas o adaptar las existentes. El presente estudio tuvo como objetivo evaluar el efecto de la colagenasa, pipeteo e incubación para disminuir la filancia del semen y su relación con la calidad espermática en alpacas para su criopreservación.

\section{Materiales Y MÉTOdos}

El estudio se llevó a cabo en el Laboratorio de Biotecnología Reproductivas de la Estación Experimental Agraria Canaán, del Instituto Nacional de Innovación Agraria (INIA), ubicado en el distrito Andrés Avelino Cáceres Dorregaray, departamento de Ayacucho, Perú. La zona se encuentra a una altitud $2735 \mathrm{msnm}$. La fase experimental tuvo una duración de tres meses (abril-junio). La alimentación de los animales fue a base de alfalfa, pasto natural y heno de avena.

Se utilizaron siete alpacas macho de 4 a 7 años, los cuales fueron entrenados para la colección de semen. Las muestras de semen se colectaron utilizando una vagina artificial que simula una presión moderada del tracto reproductivo, a $38-42{ }^{\circ} \mathrm{C}$. La vagina se colocó en un maniquí. Los eyaculados fueron colocados en forma inmediata en baño maría para evitar el shock térmico. La colección por cada animal se realizó tres veces por semana.

Se evaluaron las siguientes características macroscópicas del semen fresco:

- Color. Se realizó observando a trasluz en un tubo Falcón graduado, considerando los valores de transparente, semi lechoso y lechoso.

- Volumen. Se midió con el tubo Falcón graduado de $15 \mathrm{ml}$.

- $\quad p H$. Se determinó mediante tiras reactivas indicadoras de $\mathrm{pH}$ aplicando una gota de semen.

- Filancia. Es la formación del hilo dada por la viscosidad del semen. Se midió con una regla haciendo una extensión que se toma en cuenta desde la lámina portaobjeto hasta la ruptura del hilo, con ayuda de una pipeta de $100 \mu 1$ (Figura 1). 


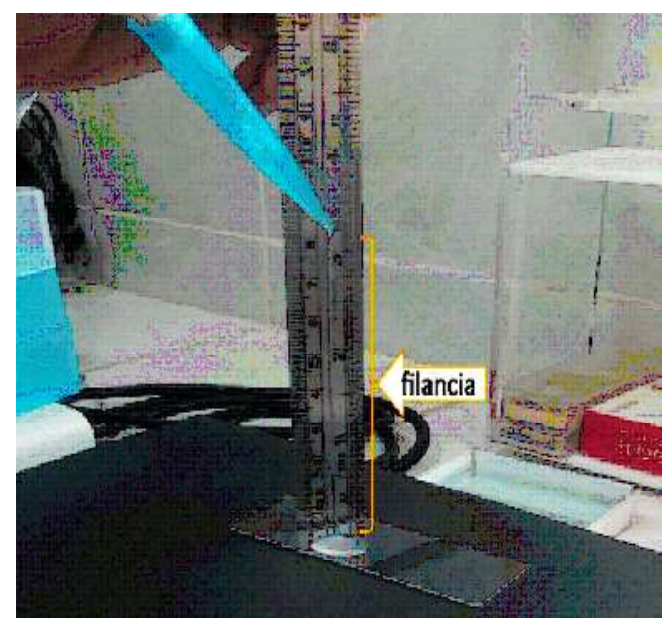

Figura 1. Determinación de la filancia seminal en la alpaca

Se evaluaron las siguientes características microscópicas del semen fresco:

- Concentración. Se determinó utilizando la cámara de Neubauer. Para ello se diluyó el semen con agua bidestilada en relación de 0.1:0.9 $\mathrm{ml}$ en un tubo eppendorf. Luego se colocó $5 \mu 1$ de la muestra en una cámara de Neubauer. Para el contaje de los espermatozoides (mill//ml) se utilizó un microscopio de contraste de fase con objetivo de 40X.

- Motilidad. Se colocó $10 \mu 1$ de semen en una lámina portaobjeto atemperada y se observó en un microscopio a 40X. Para determinar la motilidad, se consideró a todos los espermatozoides que presentaron algún tipo de movimiento (lineal o rotatorio). El resultado fue expresado en porcentaje.

- Vitalidad. Se coloca $10 \mu 1$ de semen en una lámina portaobjetos seguido de $10 \mu 1$ de eosina-nigrosina. Se homogeniza y se hace un frotis. Se cuentan 200 espermatozoides a $100 \mathrm{X}$. Se consideraron como muertos a los espermatozoides coloreados y como vivos a los no coloreados. El resultado fue expresado en porcentaje.
La muestra de semen se distribuyó en volúmenes iguales en tres tubos eppendorf y se diluyeron con el dilutor comercial AndroMed $^{\mathbb{B}}$ (Minitube) en proporción 1:1. Las muestras fueron sometidas a tratamientos químicos (T1: colagenasa), mecánico (T2: pipeteo) o físico (T3: incubación). El momento de la dilución fue considerado como tiempo 0 . Para T1, el dilutor se preparó con colagenasa al $5 \%$, para $\mathrm{T} 2$, el semen fue pipeteado 10 veces, y para T3, el semen fue incubado a $37^{\circ} \mathrm{C}$ en una placa térmica durante 10 minutos. En los tres casos, se evaluó la filancia, motilidad y vitalidad espermática a los 20, 40, 60 y 120 minutos de la dilución, manteniendo el semen en refrigeración $\left(+4{ }^{\circ} \mathrm{C}\right)$, siguiendo la metodología utilizada para el semen fresco

Para determinar los parámetros del semen fresco se utilizaron las medidas (estadígrafos) de tendencia central (promedio) y de dispersión (desviación estándar, valores mínimo y máximo). Se utilizó el análisis de varianza para evaluar el efecto de los tratamientos (químico, mecánico y físico) sobre la filancia de semen y la prueba de Duncan para determinar diferencias entre medias. Para el análisis estadístico se utilizó el programa SAS v. 9.2.

El manejo de los animales se llevó acabo de acuerdo con el código de ética para experimentos con animales (http:// ec.europa.eu/environment/chemicals/ lab_animals/legislation_en.htm).

\section{Resultados y Discusión}

Los resultados de la evaluación macro y microscópica del semen fresco se muestran en el Cuadro 1. La motilidad fue regular, no llegando a alcanzar al porcentaje aceptable $(70-80 \%)$ para ser sometido a la criopreservación, posiblemente debido a factores geográficos, método de colección y factores propios de la especie. 
Cuadro 1. Características macroscópicas y microscópicas del semen fresco de alpacas, obtenidas por vagina artificial

\begin{tabular}{lc}
\hline Característica seminal & Media \pm d.e. \\
\hline Filancia $(\mathrm{cm})$ & $1.86 \pm 1.51$ \\
Volumen $(\mathrm{ml})$ & $1.68 \pm 0.88$ \\
Motilidad $(\%)$ & $52.50 \pm 22.67$ \\
Vitalidad $(\%)$ & $70.64 \pm 8.80$ \\
Concentración $\left(\mathrm{x} 10^{6} / \mathrm{ml}\right)$ & $81.13 \pm 74.54$ \\
$\mathrm{pH}$ & $7.14 \pm 0.49$ \\
\hline
\end{tabular}

\section{Filancia}

La filancia disminuyó con el transcurso del tiempo pos-dilución (Figura 1; $<<0.05$ ), pero no fue afectado por los tratamientos realizados (Cuadro 2).

Giuliano y Casaretto (2011) y ApazaCallisaya et al. (2020) mencionan que la formación del hilo no debería utilizarse para evaluar la viscosidad, puesto que son características distintas; sin embargo, Bravo et al. (2000a) y Villanueva et al. (2018) determinaron la viscosidad seminal por medio de la filancia. Por otro lado, Mardonez y Delgado (2012) reportaron que la bromelina elimina la filancia de semen en llama, en tanto que Kershaw-Young et al. (2013) mencionan que la papaína reduce eficazmente la viscosidad seminal; no obstante, Huanca y Adams (2006) lo contradicen, puesto que tiene efectos perjudiciales sobre la integridad de los espermatozoides.

Con relación al tratamiento térmico, Bérgamo et al. (2012) evaluaron el pasaje de semen de llamas por aguja de $0.5 \mathrm{~mm}$ demostrando eficacia sobre la disminución de la filancia, en tanto que Zirena (2014) redujo la viscosidad sin alterar los parámetros seminales cuando sometió a 10 pasajes por una aguja $\mathrm{N} .{ }^{\circ} 18$ con jeringa de $5 \mathrm{ml}$ y luego centrifugado a $802 \mathrm{~g}$ por $10 \mathrm{~min}$, contradiciendo los resultados de Morton et al. (2008, 2012).

Así mismo, Giuliano y Casaretto (2011) experimentaron que el semen incubado a $37^{\circ} \mathrm{C}$ por 4 y 8 min no disminuye la filancia, mientras que Garnica et al. (1993) observaron que se elimina la vicosidad si el semen es incubado en baño maría a $37^{\circ} \mathrm{C}$ por $24 \mathrm{~h}$. Por otra parte, el semen de camello sometido a ondas ultrasónicas disminuyó la filancia y la viscosidad (Rateb, 2016).

\section{Motilidad Espermática}

No se observaron diferencias significativas entre tratamientos sobre la motilidad espermática (Cuadro 3). Asimismo, se observó una disminución de la motilidad luego de dilución $(\mathrm{p}<0.05)$ en los tres grupos; sin

Cuadro 2. Efecto del tratamiento ${ }^{1}$ del semen de alpaca sobre la filancia $(\mathrm{cm})$ según el tiempo pos-dilución

\begin{tabular}{lccccc}
\hline Tratamiento & $0 \min$ & $20 \min$ & $40 \min$ & $60 \min$ & $120 \min$ \\
\hline Colagenasa (5\%) & $0.95^{\mathrm{a}}$ & $0.71^{\mathrm{a}}$ & $0.60^{\mathrm{a}}$ & $0.49^{\mathrm{a}}$ & $0.26^{\mathrm{a}}$ \\
Pipeteo $(10 \mathrm{veces})$ & $0.89^{\mathrm{a}}$ & $0.71^{\mathrm{a}}$ & $0.53^{\mathrm{a}}$ & $0.44^{\mathrm{a}}$ & $0.27^{\mathrm{a}}$ \\
Incubación $(10 \mathrm{~min})$ & $0.91^{\mathrm{a}}$ & $0.65^{\mathrm{a}}$ & $0.65^{\mathrm{a}}$ & $0.51^{\mathrm{a}}$ & $0.33^{\mathrm{a}}$ \\
\hline
\end{tabular}

a Letras iguales dentro de columnas indican que no hay diferencia estadística significativa $(p>0.05)$

1 Tres observaciones por tiempo de pos-dilución y por tratamiento 
Cuadro 3. Efecto del tratamiento ${ }^{1}$ del semen de alpaca sobre la motilidad (\%) según el tiempo pos-dilución

\begin{tabular}{lccccc}
\hline Tratamiento & $0 \mathrm{~min}$ & $20 \mathrm{~min}$ & $40 \mathrm{~min}$ & $60 \mathrm{~min}$ & $120 \mathrm{~min}$ \\
\hline Colagenasa (5\%) & $38.04^{\mathrm{a}}$ & $38.57^{\mathrm{a}}$ & $36.43^{\mathrm{a}}$ & $35.18^{\mathrm{a}}$ & $33.21^{\mathrm{a}}$ \\
Pipeteo (10 veces) & $35.36^{\mathrm{a}}$ & $33.57^{\mathrm{a}}$ & $36.25^{\mathrm{a}}$ & $33.39^{\mathrm{a}}$ & $31.25^{\mathrm{a}}$ \\
Incubación (10 min) & $35.54^{\mathrm{a}}$ & $35.36^{\mathrm{a}}$ & $32.68^{\mathrm{a}}$ & $33.93^{\mathrm{a}}$ & $31.25^{\mathrm{a}}$ \\
\hline
\end{tabular}

a Letras iguales dentro de columnas indican que no hay diferencia estadística significativa $(p>0.05)$

${ }^{1}$ Tres observaciones por tiempo de pos-dilución y por tratamiento

Cuadro 4. Efecto del tratamiento ${ }^{1}$ del semen de alpaca sobre la vitalidad espermática (\%) según el tiempo pos-dilución

\begin{tabular}{lccccc}
\hline Tratamiento & $0 \min$ & $20 \min$ & $40 \min$ & $60 \min$ & $120 \min$ \\
\hline Colagenasa (5\%) & $72.61^{\mathrm{a}}$ & $69.86^{\mathrm{a}}$ & $71.25^{\mathrm{a}}$ & $69.64^{\mathrm{a}}$ & $67.46^{\mathrm{a}}$ \\
Pipeteo (10 veces) & $71.96^{\mathrm{a}}$ & $69.00^{\mathrm{a}}$ & $71.93^{\mathrm{a}}$ & $69.96^{\mathrm{a}}$ & $69.07^{\mathrm{a}}$ \\
Incubación (10 min) & $72.21^{\mathrm{a}}$ & $69.96^{\mathrm{a}}$ & $69.29^{\mathrm{a}}$ & $70.32^{\mathrm{a}}$ & $65.39^{\mathrm{a}}$ \\
\hline
\end{tabular}

a Letras iguales dentro de columnas indican que no hay diferencia estadística significativa $(p>0.05)$

${ }^{1}$ Tres observaciones por tiempo de pos-dilución y por tratamiento

embargo, posterior a ello solo hubo una ligera diminución durante el tiempo pos-dilución del estudio (Figura 3).

Se reporta que el tratamiento con colagenasa para disminuir la filancia afecta la motilidad espermática y la integridad acrosomal (Bravo et al., 2000a; Rateb, 2016); no obstante, Giuliano y Casaretto (2011) observaron que mejoró la movilidad progresiva además de conservar la integridad funcional de la membrana plasmática de los espermatozoides. En tanto, Fumuso et al. (2015) mencionan que los tratamientos enzimáticos podrían modificar el patrón de movilidad, interfiriendo la interacción ovocito-espermatozoide comprometiendo la unión de los gametos.

Saltos (2007) y Zirena (2014) mencionan que el pasaje del semen por una aguja y la centrifugación con fines de reducir la vis- cosidad seminal afectan negativamente la motilidad espermática; no obstante, GómezQuispe et al. (2019) centrifugando el semen a $700 \mathrm{~g}$ por $7 \mathrm{~min}$ obtuvieron una alta tasa de espermatozoides móviles con adecuada integridad funcional de la membrana plasmática. Así mismo, Morton et al. (2008, 2012) reportaron que el pipeteo suave no compromete la motilidad espermática. Por otro lado, Giuliano y Casaretto (2011) reportan que la incubación del semen durante 8 min mejoró la motilidad progresiva del espermatozoide, y Rateb (2016) utilizando el ultrasonido como tratamiento observó que hubo mayor motilidad espermática.

\section{Vitalidad Espermática}

No se observaron diferencias significativas entre tratamientos sobre la vitalidad espermática (Cuadro 4). Asimismo, solo se 


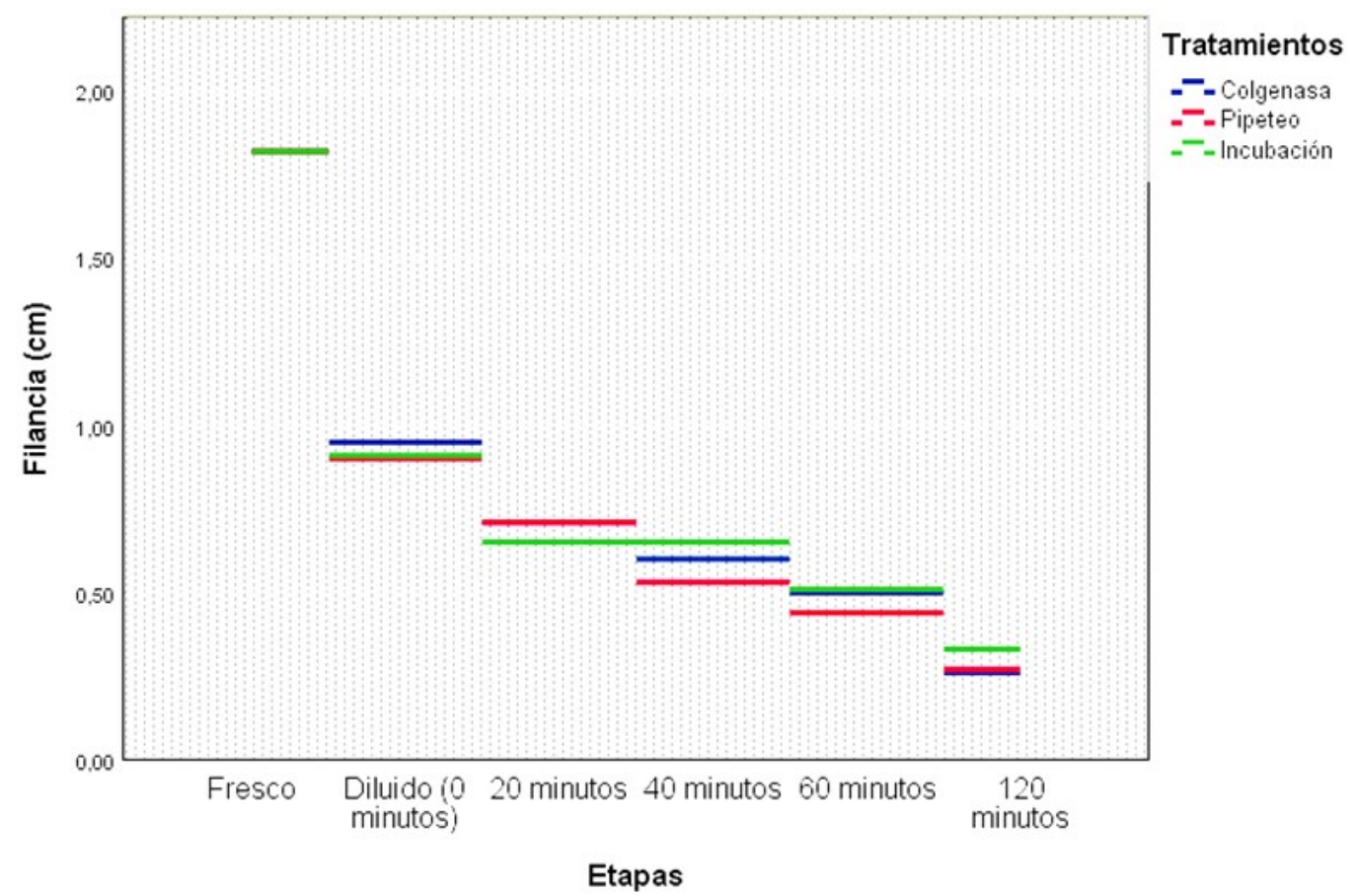

Figura 2. Comportamiento de la filancia seminal de alpacas pos-dilución del semen según los tratamientos efectuados en el semen

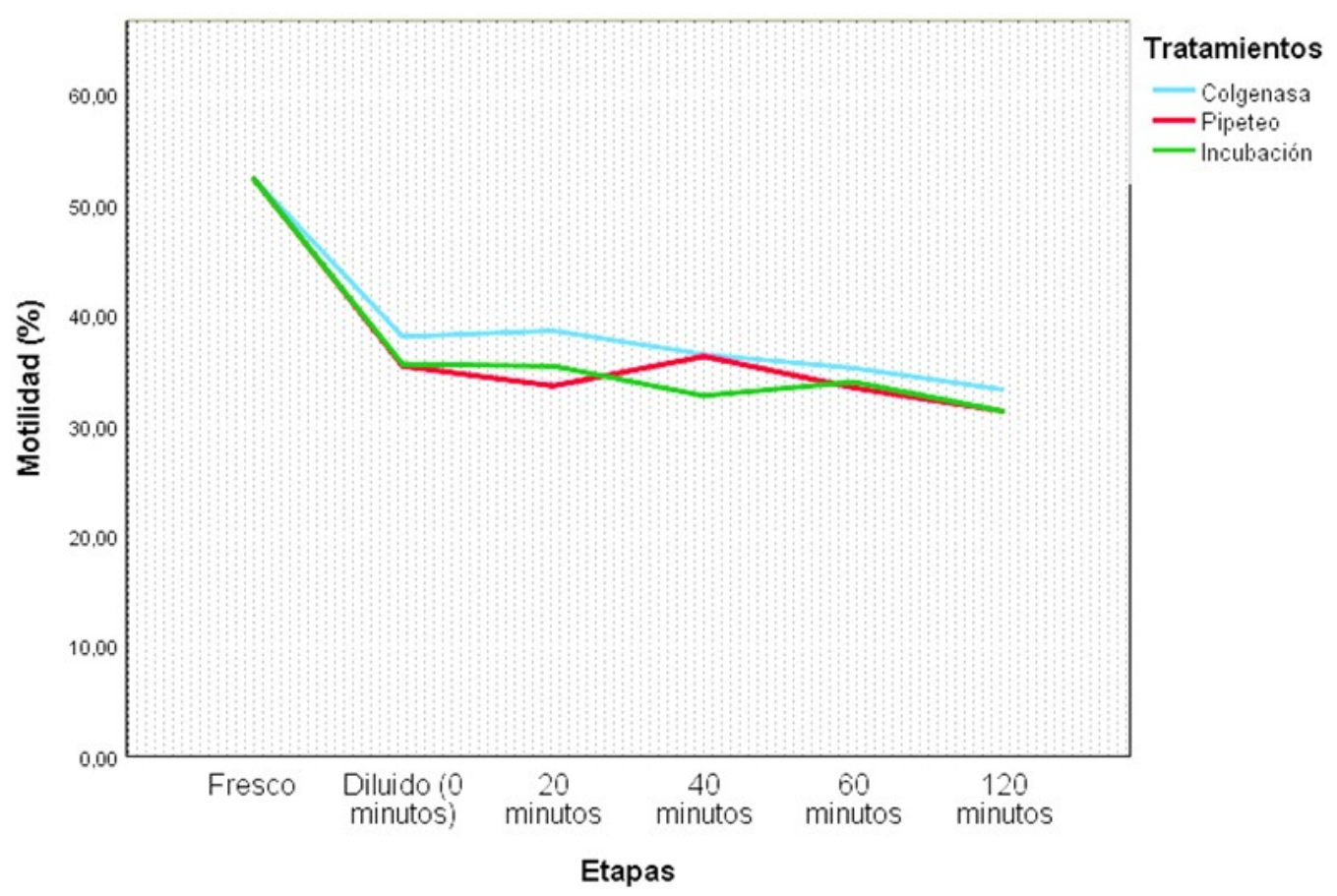

Figura 3. Comportamiento de la motilidad espermatica de alpacas pos-dilución del semen según los tratamientos efectuados en el semen en cada tiempo (etapa) de los tratamientos 


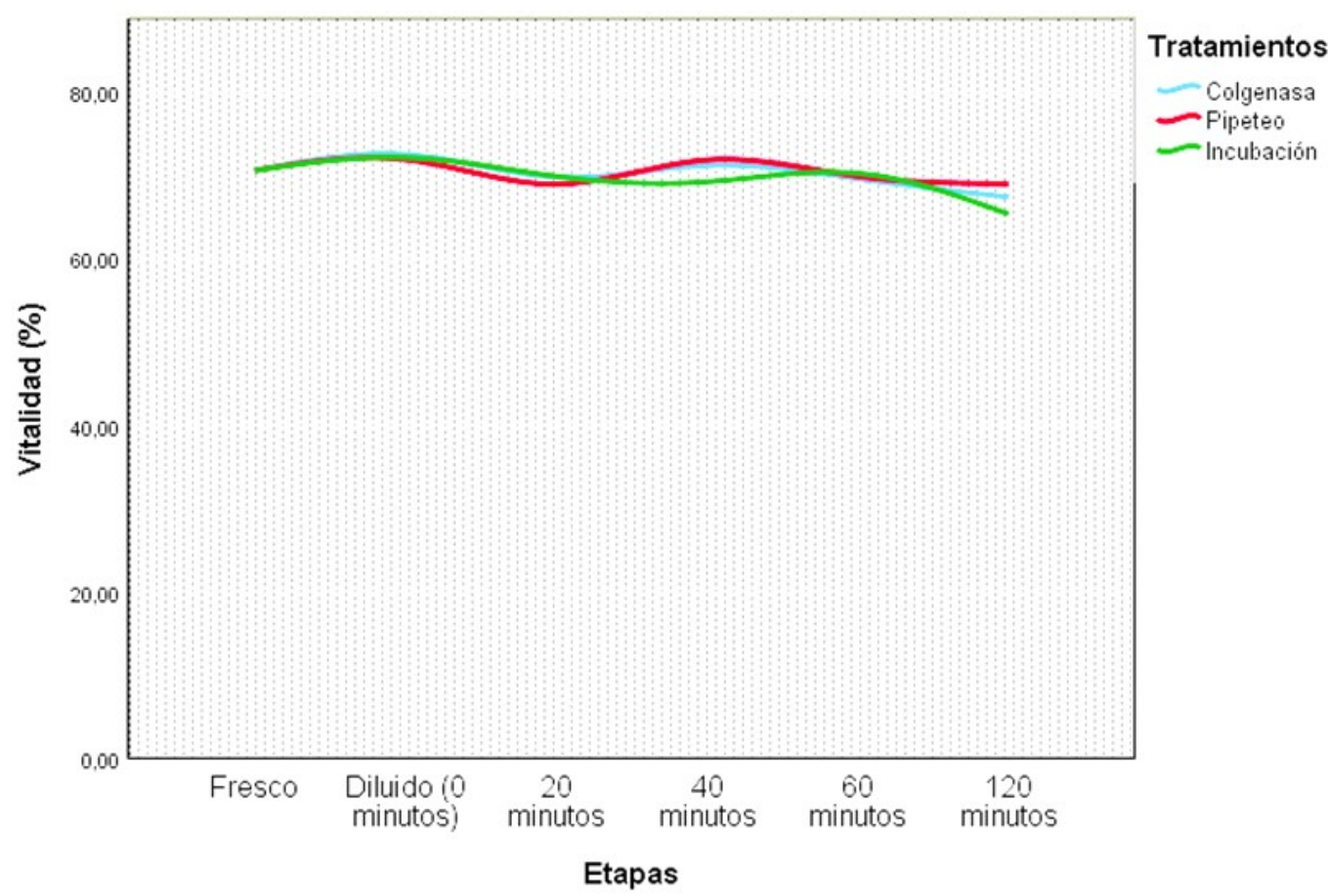

Figura 4. Comportamiento de la vitaliadad espermatica en alpacas en cada tiempo (etapa) según los tratamientos

observó una ligera variabilidad en la vitalidad espermática entre el semen fresco y el semen diluido durante el tiempo del estudio (Figura 4),

En estudios similares, Bravo et al. (2000a) y Morton et al. (2012) utilizando colagenasa y tripsina observaron ligera disminución del porcentaje de espermatozoides vivos. Por otro lado, Rateb (2016) observó que el semen tratado con ultrasonido registró mayor porcentaje de viabilidad. No obstante, investigaciones recientes concluyen que la perdida de motilidad progresiva no solo sea debido a la acción mecánica, sino a efectos más complejos (Giuliano et al., 2010; Giuliano, 2012; Carretero et al., 2015, 2017).

\section{Conclusión}

El tratamiento enzimático, mecánico y físico, como la colagenasa, pipeteo e incubación, disminuyeron la filancia del semen de alpaca pos-dilución, afectando la motilidad y vitalidad espermática.

\section{Agradecimiento}

Al personal especialista y asistentes encargados del Laboratorio de Biotecnología Reproductiva de la Estación Experimental Agraria Canaán y a la Universidad Nacional de San Cristóbal de Huamanga por promover el desarrollo de este estudio. Al PNIA por el financiamiento del proyecto de investigación en biotecnología reproductiva en CSA. 


\section{Literatura Citada}

1. Allauca P, Ugarelli U, Santiani A. 2019. Determinación del potencial de membrana mitocondrial mediante citometría de flujo durante el proceso de criopreservación de espermatozoides epididimarios de alpacas. Rev Inv Vet Perú 30: 288-298. doi: 10.15381/rivep.v30i1.15677

2. Aller J, Rebuffi G, Cancino A, Alberio $R$. 2003. Influencia de la criopreservación sobre la motilidad, viabilidad y fertilidad de espermatozoides de llama (Lama glama). Arch Zootec 52: 15-23.

3. Apaza-Callisaya BN, Loza-Murguia MG, Quispe-Paxipati CH, MachicadoGómez RM, Achu-Nina C. 2020. Parámetros cinéticos de espermatozoides en semen fresco y crioconservado de alpaca (Vicugna pacos L.). J Selva Andina Anim 7: 17-29.

4. Apaza N, Sapana R, Huanca T, Huanca $W$. 2001. Inseminación artificial en alpacas con semen fresco en comunidades campesinas. Rev Inv Vet Perú 23: 435-438.

5. Bérgamo N, Medina VH, Martínez CY, Vagnoni YC, Aisen EG. 2012. Efecto de diferentes métodos de reducción de la filancia en el semen de Lama glama. En: VI Congreso Mundial de Camélidos Sudamericanos. Arica.

6. Bravo PW, Alarcón V, Baca L, Cuba Y, Ordoñez, C, Salinas J, Tito F. 2013. Semen preservation and artificial insemination in domesticated South American camelids. Anim Reprod Sci 136: 157-163. doi: 10.1016/j.anireprosci.-2012.10.005

7. Bravo PW, Ccallo M, Garnica J. 2000. The effect of enzymes on semen viscosity in llamas and alpacas. Small Ruminant Res 38: 91-95. doi: 10.1016/ s0921-4488(00)00142-5

8. Bravo PW, Skidmore JA, Zhao XX. 2000. Reproductive aspects and storage of semen in camelidae. Anim Reprod Sci 62: 173-193. doi: 10.1016/s0378-4320(00)00158-5
9. Cabrera P, Yoong W. 2009. Evaluación de la fertilidad in vitro del semen de toros jóvenes nacionales en ovocitos provenientes de ovarios de animales beneficiados. Rev Inv Vet Perú 20: 28-32.

10. Carretero M, Giuliano M, Neild D. 2017. Evaluación de la calidad del ADN espermático en camélidos sudamericanos y otras especies domésticas. Spermova 7: 18-26.

11. Carretero M, Neild DM, Ferrante A, Caldevilla M, Arraztoa CC, Fumuso FG, Giuliano SM. 2015. Effect of cryoprotectant and equilibration temperature on cryopreservation of Lama glama spermatozoa. Andrologia 47: 685693. doi: 10.1111/and.12319

12. Ciprian R. 2018. Criopreservación de semen del semen de alpaca utilizando metil-â-ciclodextrina cargado con colesterol. Tesis de Magíster. Lima, Perú: Univ. Nacional Agraria La Molina. $79 \mathrm{p}$.

13. Delgado P, Quispe Y. 2015. Efecto de tres niveles de glicerol y tiempos de equilibramiento sobre la viabilidad de espermatozoides de llama (Lama glama) post- descongelado. Rev Inv Altoandinas 17:445-448.

14. Elsayed DH, El-Shamy AA, Abdelrazek HMA, El-Badry DA. 2019. Effect of genistein on semen quality, antioxidant capacity, caspase-3 expression and DNA integrity in cryopreserved ram spermatozoa. Small Ruminant Res 177: 50-55. doi: 10.1016/ J.SMALLRUMRES.2019.06.009

15. Fumuso F, Carretero M, Miragaya M, Giuliano S. 2015. Effect of seminal plasma on the sperm motility patterns and their relationship to the cryopreservation of llama semen. Spermova 5: 229-233.

16. Garnica J, Achata R, Bravo P. 1993. Physical and biochemical characteristics of alpaca semen. Anim Reprod Sci 32: 8590. doi: 10.1016/0378-4320(93)90059-Z

17. Giuliano M, Casaretto C. 2011. Uso de colagenasa mejora las características seminales de llamas (Lama glama). Spermova 1: 64-65 
18. Giuliano S. 2012. Extracción y evaluación de semen de camélidos sudamericanos. Spermova 2: 6-9.

19. Giuliano S, Carretero M, Gambarotta $M$, Neild D, Trasorras V, Pinto M, Miragaya M. 2010. Improvement of llama (Lama glama) seminal characte.ristics using collagenase. Anim Reprod Sci 118: 98-102. doi: 10.1016/j.anireprosci.2009.06.005

20. Gómez-Quispe O, Guido Pérez M, Machaca V. 2016. Adición del antioxidante Tempol en la criopreservación de espermatozoides de alpaca (Vicugna pacos) colectados por desviación del conducto deferente. Rev Inv Vet Perú 27: 294-302. doi: 10.15381/ rivep.v27i2.11642

21. Gómez-Quispe OE, GutiérrezReynoso GA, Gallegos-Cardenas A, Fumuso FG, Asparrin M, AsparrinDel Carpio M, Jara CW, 2019. Motility and recovery of alpaca (Vicugna pacos) spermatozoa after centrifugation in a density gradient solution. Iran J Vet Res 20: 96-104.

22. Gonzáles V. 2003. Efecto de la bulbouretrectomia y frecuencia de colección en las características macro y microscópicas del eyaculado de llama (Lama glama). Tesis de Ingeniero Zootecnista. La Paz, Bolivia: Universidad Católica Boliviana. $70 \mathrm{p}$.

23. Hafez E. 2002. Reproducción e inseminación artificial en animales. $7^{\circ}$ ed. México: McGraw Hill Interamericana. $512 \mathrm{p}$.

24. Huanca W, Adams G. 2006. Semen collection and artificial insemination in llamas and alpacas. In: Current therapy in large animal theriogenology.

25. Huanca W, Cordero A, Huanca T, Adams G 2007. Biotecnología reproductivas en camélidos sudamericanos domésticos: avances y perspectivas. Arch Latinoam Prod Anim 15: 195-201.

26. Kershaw-Young CM, Stuart C, Evans G, Maxwell WM. 2013. The effect of glycosaminoglycan enzymes and proteases on the viscosity of alpaca seminal plasma and sperm function. Anim Reprod Sci 138: 261-267. doi: 10.1016/j.anireprosci.2013.02.005

27. Mardonez J, Delgado P. 2012. Efecto de seis enzimas sintéticas y naturales sobre las características macro-microscópicas en semen de llama (Lama glama). En: VI Congreso Mundial de Camélidos Sudamericanos. Arica, Chile.

28. Morton K, Gibb Z, Leahy T, Maxwell $W .2012$. Effect of enzyme treatment and mechanical removal of alpaca (Vicugna pacos) seminal plasma on sperm functional integrity. J Camelid Sci 5: 62-81.

29. Morton KM, Thomson PC, Bailey K, Evans G, Maxwell WM. 2010. Quality parameters for alpaca (Vicugna pacos) semen are affected by semen collection procedure. Reprod Domest Anim 45: 637-643. doi: $10.1111 /$ j.1439-0531.2008.01321.x

30. Morton K, Vaughan J, Maxwell W. 2008. Continued development of artificial insemination technology in alpacas. Australia: RIRDC. 189 p.

31. Mostafa T, El-Salaam A, Elbadry D, Abear M. 2014. Freezability and DNA integrity of dromedary camel spermatozoa in semen collected by artificial vagina and electro-ejaculator. Egypt J Agric Res 51: 145-155. doi: 10.21608/ ejap. 2014.93660

32. Muchotrigo D. 2017. Efecto de la adición de Tempol y catalasa al dilutor para la criopreservacion de semen de alpaca. Tesis del Médico Veterinario y Zootec-nista, Lima, Perú: Univ. Científica del Sur. 43 p.

33. Quispe U, Huanca T, Olivera L. 2019. Influencia de las hormonas folículo estimulante, luteinizante y gonadotropina coriónica equina en la maduración in vitro de ovocitos y clivaje de embriones de alpaca. Rev de Investigaciones UNA 8: 974-985. doi: 10.26788/epg.v8i1.774

34. Rateb $S A$. 2016. Ultrasound-assisted liquefaction of dromedary camel semen. Small Ruminant Res 141: 48-55. doi: 10.1016/j.smallrumres.2016.07.005 
35. Saltos C. 2007. Efecto de la centrifugación en la motilidad espermática del semen equino refrigerado. Tesis de Médico Veterinario. Quito, Ecuador: Univ. San Francisco de Quito. 70 p.

36. Stornelli M, Tittarelli M, Savignone C, Stornelli M. 2005. Efecto de los procesos de criopreservación sobre la fertilidad seminal. Analecta Vet 25: 28-35.

37. Tortolero I, Arata-Bellabarba G Osuna JA, Gómez R, Regadera J. 2005. Estrés oxidativo y función esper-mática. Rev Ven Endocrinol Metab 3: 12-19.

38. Turín J, Madrid N, Aranguren JA, Limache T, Huanca W. 2013. Efecto de la remoción del plasma seminal y centrifugación sobre la calidad de los espermatozoides descongelados de alpacas (Lama pacos). En: Mem XXXVI Reunión Científica Anual de la Asociación Peruana de Producción Animal. Lima, Perú

39. Villanueva JC, Huanca WF, Hilari F, Uchuari M, Rodríguez F, Huanca W. 2018. Efecto de la estación sobre las características seminales de alpacas (Vicugna pacos) criadas a nivel del mar. Rev Inv Vet Perú 29: 559-564. doi: 10.15381/rivep.v29i2.14483

40. Zirena N. 2014. Comparación de dos métodos físicos en el tratamiento del semen fresco de alpacas y su relación con la calidad espermática post congelación. Tesis de Médico Veterinario. Lima, Perú: Univ. Nacional Mayor de San Marcos. 61 p. 